\title{
Studies of granulosa cell maturation in dominant and subordinate bovine follicles: novel extracellular matrix focimatrix is co-ordinately regulated with cholesterol side-chain cleavage CYP11A1
}

\author{
H F Irving-Rodgers ${ }^{1}$, M L Harland ${ }^{1}$, T R Sullivan ${ }^{2}$ and R J Rodgers ${ }^{1}$ \\ ${ }^{1}$ Research Centre for Reproductive Health, Discipline of Obstetrics and Gynaecology and ${ }^{2}$ Data Management and \\ Analysis Centre, Discipline of Public Health, University of Adelaide, Adelaide, South Australia 5005, Australia
}

Correspondence should be addressed to R J Rodgers; Email: ray.rodgers@adelaide.edu.au

\begin{abstract}
During growth of antral ovarian follicles granulosa cells first become associated with a novel type of extracellular matrix, focimatrix, and at larger sizes follicles become either subordinate or dominant. To examine this, bovine subordinate (9.0 \pm S.E.M. 0.4 mm; $n=16)$, partially dominant $(12.0 \pm 0.6 \mathrm{~mm} ; n=18)$ and fully dominant $(15.0 \pm 0.4 \mathrm{~mm} ; n=14)$ follicles were examined by real time RT-PCR analyses of granulosa cells and by immunohistochemistry of focimatrix. Changes in the expression of FSH receptor, LH receptor,

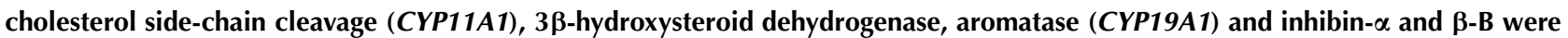
observed as expected for follicle sizes examined. After adjusting for size differences, only CYP11A1 was significantly different between the groups, and elevated in dominant follicles. Also after adjusting for differences in size there were no significant differences in expression of focimatrix components collagen type IV $\alpha-1$ (COL4A1), laminin $\beta-2$, nidogen 1 (NID1), and perlecan (HSPG2) or the volume density of NID1 and -2 and HSPG2. The volume density of focimatrix components in laminin 111 was significantly elevated in dominant follicles. Adjusting for analysis of more than one follicle per animal and for multiple correlations, CYP11A1 mRNA levels were highly correlated with the focimatrix genes COL4A1, NID1 and -2 and HSPG2. Thus, focimatrix may potentially regulate CYP11A1 expression, and the regulation of both could be important in follicular dominance.

Reproduction (2009) 137 825-834
\end{abstract}

\section{Introduction}

Growth and development of ovarian follicles from primordial to large antral stages is essential for production of mature oocytes and secretion of ovarian steroid hormones. However, the growth and development of follicles within ovaries involves complex dynamics. During growth, follicles sequentially undergo recruitment (initial and cyclic), selection, dominance and ovulation (or atresia). Initial recruitment is a slow growth phase in comparison with cyclic recruitment (Lussier et al. 1987). Once cyclic recruitment commences groups of antral follicles grow as in a 'wave'. The first wave of an oestrous cycle is initiated 1-2 days after ovulation (Valdez et al. 2005) and the number of follicular waves per cycle (2 or 3 ) is determined by the duration of the luteal phase (Fortune 1994). Large variation exists between animals in terms of number of follicles per wave (range 11-54), principally due to differences in the numbers of small follicles (those $\sim 3 \mathrm{~mm}$ in diameter). The number of follicles per wave is relatively consistent within individual cows and does not correlate with either two or three wave patterns per oestrous cycle, or with dominant follicle development (Burns et al. 2005). In each follicular wave, the future dominant follicle enters the wave $\sim 6 \mathrm{~h}$ earlier than other follicles in the cohort, which translates into a size advantage at the end of the common growth phase (Jaiswal et al. 2004). Since all follicles of the common growth phase have potential for future dominance, selection of the dominant follicle is likely to involve suppression of other (subordinate) follicles (Ginther et al. 2003). As the wave progresses and the dominant follicle grows the subordinate follicles undergo atresia. If the wave is in the luteal phase no surge release of $\mathrm{LH}$ can occur and the dominant follicle becomes atretic. A new wave of follicle development follows, and if this is at the end of the luteal phase then that dominant follicle can ovulate in response to a surge release of $\mathrm{LH}$.

The principal hormone controlling follicular growth is $\mathrm{FSH}$, which in turn is negatively controlled by oestradiol and inhibin- $\alpha$ (INHA) secreted from the large-dominant follicle (Campbell et al. 2003). Thus, the FSH 
concentration is lower (Ginther et al. 1997, 2003, Berisha et al. 2000) when deviation in the growth rate between dominant and subordinate follicles manifests as a size difference between them. During follicle selection, increasing expression of the FSH receptor (FSHR) in granulosa cells precedes increased expression of the $\mathrm{LH}$ receptor (LHCGR; Berisha et al. 2000) which is first detected only in healthy follicles $>9 \mathrm{~mm}$ in diameter (Xu et al. 1995). Thus, LHCGR expression in granulosa cells occurs after selection and ensures the continued growth of the dominant follicle as the circulating concentration of $\mathrm{FSH}$ falls and subordinate follicles regress. However, FSH is still important as exposure to FSH in the absence of $\mathrm{LH}$ can still support the growth of follicles $>10 \mathrm{~mm}$ in diameter (Crowe et al. 2001, Hampton et al. 2004). LH also stimulates thecal cell androgen secretion and combined with increasing cytochrome P450aromatase (CYP19A1) expression and activity in granulosa cells, oestradiol production from the dominant follicle increases (Fortune et al. 2001). As the dominant follicle matures granulosa cells also express cholesterol side-chain cleavage cytochrome P450 (CYP11A1) and 3 $\beta$-hydroxysteroid dehydrogenase (HSD3B) increasing their ability also to produce progesterone (Tian et al. 1995). These changes in granulosa cells whereby they become steroidogenic are generally referred to as maturation.

While externally follicle growth and development and granulosa cell maturation are under the control of the pituitary gonadotrophins, internally growth factors and cell-cell and cell-matrix contacts are also important. Very little research has been conducted on the roles of matrix. However, a novel type of basal lamina matrix, called focimatrix (focal intra-epithelial matrix; Irving-Rodgers et al. 2004), developmentally appears about 10 days before ovulation in the cow. Focimatrix (illustrated in Fig. 1) is deposited as plaques or aggregates of basal lamina material between the epithelial granulosa cells in follicles $>5 \mathrm{~mm}$ in diameter in bovine and its abundance increases as follicles enlarge. Although discovered in the bovine, focimatrix also exists in sheep (Huet et al. 1997) and humans (Yamada et al. 1999, Alexopoulos et al. 2000). The novel aspect of this matrix is its conformation. Basal laminas are normally a sheet of matrix 'wrapped' around a cell or a group of cells (epithelia or endothelia). Therefore, basal laminas make compartments within tissues. Focimatrix, however, does not form a continuous layer and thus it cannot perform known basal lamina functions. Focimatrix in the cow is composed of aggregates of basal lamina material (collagen type IV $\alpha-1$ (COL4A 1$)$ and $\alpha-2$, laminin chains $\alpha-1, \beta-2$ (LAMB2) and $\gamma-1$, perlecan (HSPG2), and nidogens 1 and 2 (NID1 and -2). It is degraded at ovulation (Irving-Rodgers et al. 2006a) as granulosa cells commence terminal differentiation into luteal cells and hence does not exist in human or bovine corpora lutea (Irving-Rodgers et al. 2004, 2006b). Thus, focimatrix is

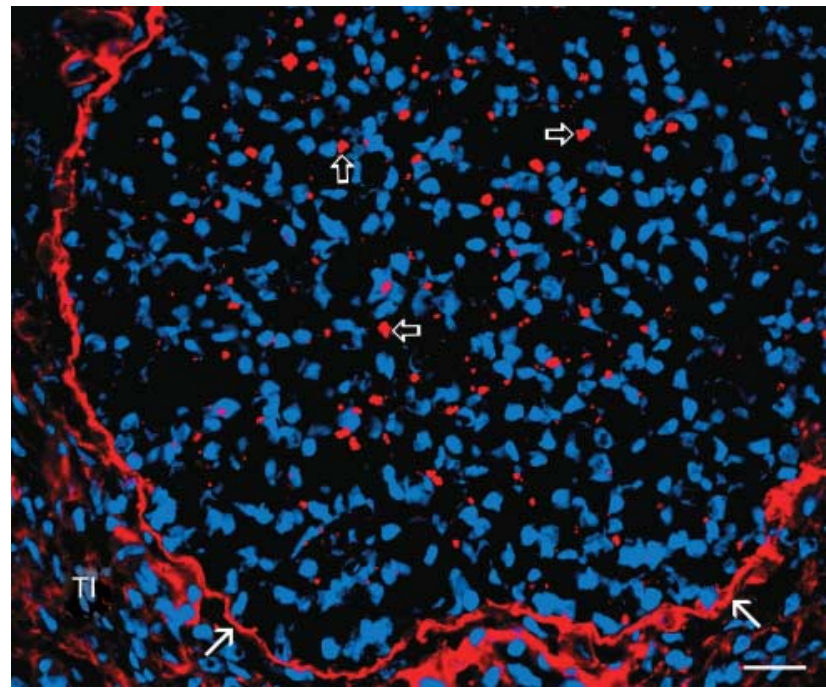

Figure 1 Laminin 111 components are localised (red) to focimatrix (open arrows) within the membrana granulosa, the follicular basal lamina (arrows) and subendothelial basal laminas in the theca interna (TI). Nuclei; DAPI counterstain (blue). Scale bar $=20 \mu \mathrm{m}$.

developmentally regulated and is present before, and then during, the follicular phase when granulosa cells mature to produce progesterone and oestradiol and at the same time when follicles become dominant or subordinate.

To investigate whether focimatrix has a role either in the selection and dominance of ovarian follicles and/or in the maturation of granulosa cells, we examined healthy subordinate, partially dominant (the largest healthy follicle, but next largest is still healthy) and fully dominant (the largest healthy follicle, but next largest is atretic) bovine follicles. We undertook immunohistochemical analysis of focimatrix components in the membrana granulosa of these follicles, and examined expression of markers of granulosa cell maturation (gonadotrophin receptors, inhibins, steroidogenic enzymes) and focimatrix components.

\section{Results}

Fully dominant follicles were significantly $(P=0.0002)$ larger $(16.0 \pm 0.5 \mathrm{~mm}$; mean \pm S.E.M. $)$ than partially dominant follicles $(12.0 \pm 0.5 \mathrm{~mm})$, which in turn were significantly $(P<0.0001)$ larger than subordinate follicles $(9.5 \pm 0.5 \mathrm{~mm}$; Fig. $2 \mathrm{~A})$. The diameter of dissected follicles can be up to $3 \mathrm{~mm}$ greater than that estimated by ultrasound, since the latter measures only the antral cavity (Quirk et al. 1986, Evans \& Fortune 1997). Real time RT-PCR analyses showed that mRNA levels for the FSHR did not differ between these follicle groups (Fig. 2B) while mRNA levels for the LHGCR were significantly greater in fully dominant follicles in comparison with partially dominant.$(P=0.0014)$ and subordinate follicles $(P=0.0002$; Fig. 2C). However, 
A
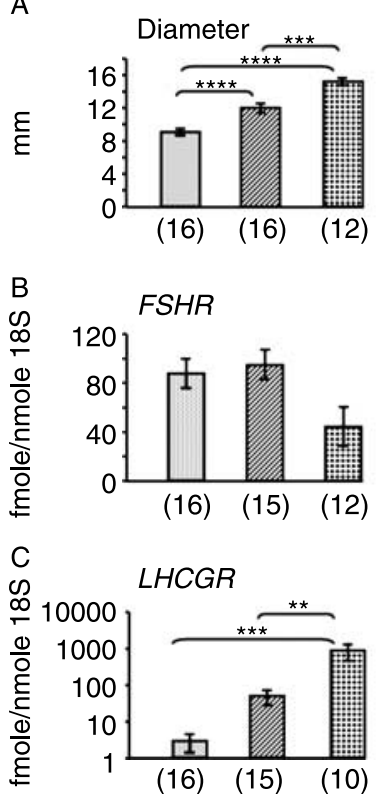

D

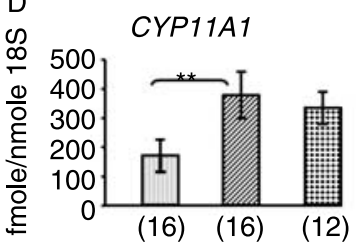

E

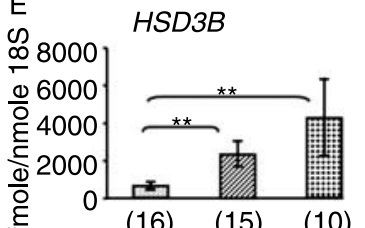

(16) (15) (10)

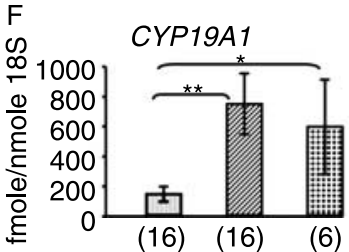

Subordinate

Partially dominant

Fully dominant
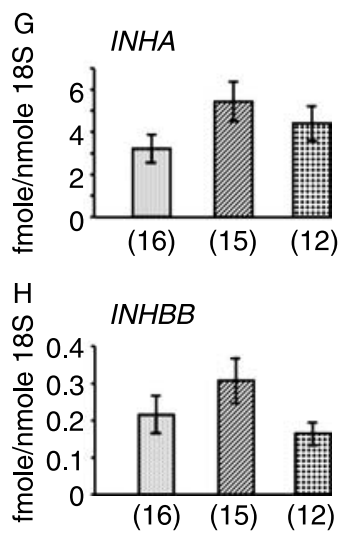

Figure 2 Mean \pm s.E.M. diameter of follicles (A), and the levels of mRNA relative to $18 \mathrm{~S}$ rRNA in granulosa cells of (B) FSHR, (C) LHCGR (log scale), (D) CYP11A1, (E) HSD3B, (F) CYP19A1, (G) INHA and (H) INHBB in subordinate, partially dominant and fully dominant follicles (numbers of follicles are shown in parentheses). ${ }^{*} P<0.05 ;{ }^{* *} P<0.01 ;{ }^{* * *} P<0.001$ significantly different prior to adjusting for differences in diameters between groups. For statistical analyses the data in $(C),(D),(E)$ and $(F)$ were log transformed.

after adjusting for differences in follicle diameter, there were no longer any significant differences between the three follicle groups. mRNA levels for CYP11A1 were significantly lower in subordinate follicles in comparison with dominant follicles ( $P=0.004$; Fig. 2D) and this effect was maintained following adjustment for follicle size $(P=0.01)$. mRNA levels for HSD3B and CYP19A1 were significantly lower in subordinate follicles in comparison with either partially or fully dominant follicles (Fig. 2E and F) but after adjusting for follicle diameter there were no longer any significant differences. mRNA levels for INHA $(P=0.071)$ and INHBB $(P=0.72)$ did not differ significantly between follicles (Fig. $2 \mathrm{G}$ and $\mathrm{H}$ ).

The mRNA levels of COLAA1, LAMB2, HSPG2 and NID1 did not differ significantly between follicles (Fig. 3A-D), however, mRNA levels for NID2 were significantly $(P<0.01)$ lower in partially dominant follicles in comparison with fully dominant $(P=0.0072)$ or subordinate $(P=0.0018)$ follicles, and this effect was still significant after adjusting for follicle size ( $P=0.0182$ and $P=0.0323$ respectively; Fig. $3 \mathrm{E}$ ).

Estimation of the volume density of focimatrix (laminin 111, NID1 and -2, and HSPG2) by image analysis of immunostained sections showed that the amount of laminin (as detected with anti-laminin 111) was significantly lower in subordinate follicles in comparison with partially $(P<0.001)$ or fully $(P=0.0007)$ dominant follicles (Fig. 4A). Following adjustment for follicle size this effect remained ( $P=0.07$ and $P=0.001$ respectively). The amounts of NID1 and -2 and HSPG2 did not differ significantly $(P>0.05)$ between groups (Fig. 4B-D).
Correlation analyses were conducted using follicle size and gene expression data, accounting for dependence between observations from the same animal (since 2 or 3 follicles were collected per animal), and

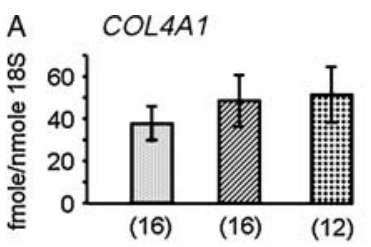

Subordinate
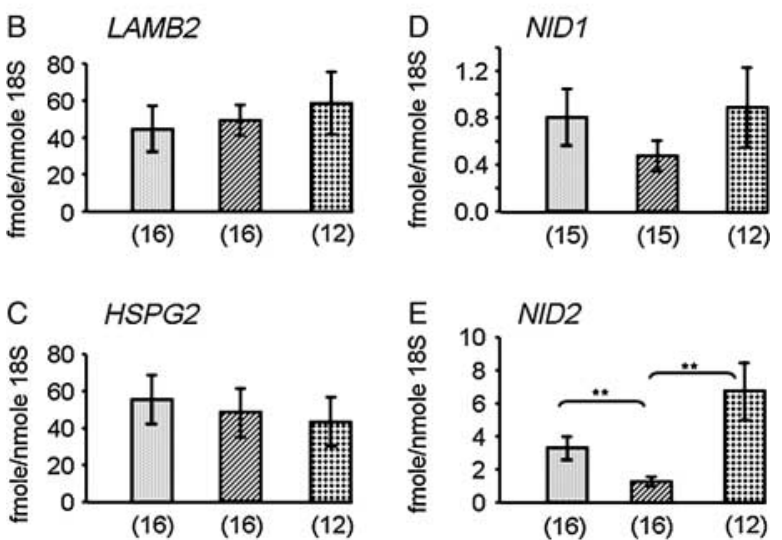

Figure 3 Mean \pm S.E.M. levels of mRNA relative to $18 \mathrm{~S}$ rRNA in granulosa cells of (A) COL4A1, (B) LAMB2, (C) HSPG2, (D) NID1 and (E) NID2 and in subordinate, partially dominant and fully dominant follicles (numbers of follicles are shown in parentheses). ${ }^{* *} P<0.01$ significantly different prior to adjusting for differences in diameters between groups. For statistical analyses the data in (C), (D) and (E) were log transformed. 

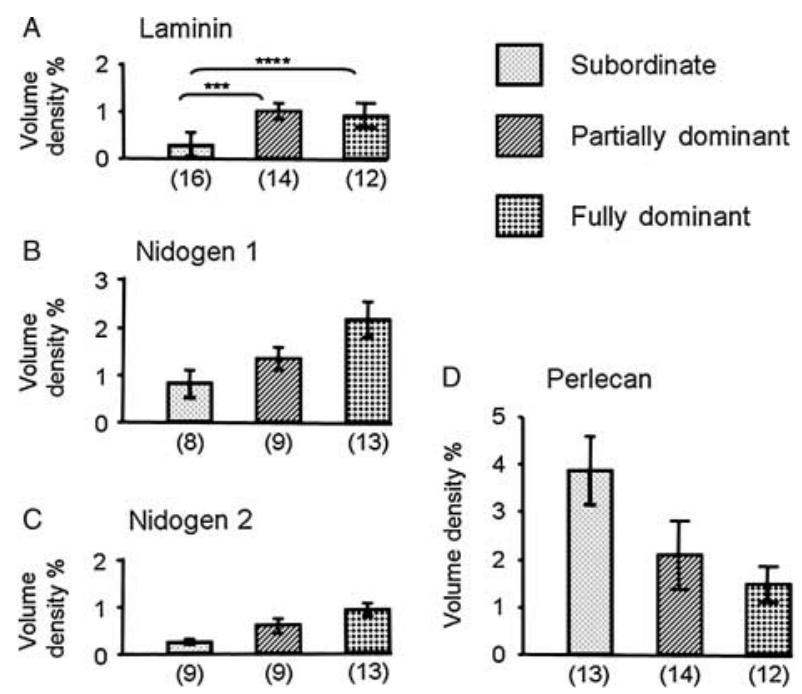

Figure 4 Volume density of (A) laminin (detected using anti EHS laminin 111), (B) nidogen 1 (C) nidogen 2 and (D) perlecan in the membrana granulosa of subordinate, partially dominant and fully dominant follicles (numbers of follicles are shown in brackets). ${ }^{* * *} P<0.001$; **** $P<0.0001$ significantly different prior to adjust for differences in initially log transformed.

corrected for multiple comparisons. The correlation coefficients and their significance values are shown in Table 1 and examples shown in Fig. 5. The expression of levels of COL4A1, NID1 and -2 and HSPG2 were very significantly correlated with each other (Table 1 and Fig. 5), and $\angle A M B 2$ was less significantly correlated with COL4A1 and HSPG2. LHCGR correlated with follicle size and extracellular matrix components (COL4A1, NID1 and -2 and HSPG2, but not LAMB2; Table 1 and Fig. 5). Interestingly, CYP11A1 correlated with CYP19A1 and also with $L A M B 2, H S P G 2$ and COL4A1 (Table 1 and Fig. 5). Neither FSHR nor LHCGR correlated with any steroidogenic enzyme (Table 1).

By accounting for dependence between observations from the same animal these statistical analyses effectively average observations across all the follicles for each animal. Thus, individual correlations were additionally conducted separately for each follicle group thereby ensuring that only one follicle per animal was included in each analysis (Table 2 shows data for partially dominant follicles). Qualitatively similar correlation relationships were observed in the partially dominant subset of follicles, but additionally CYP19A1 expression correlated with $L H C G R, N I D 1$ and -2 , HSPG2 and COL4A1 but not LAMB2. In subordinate follicles, there was no association between CYP11A1 and CYP19A1 with the focimatrix components (shown in Supplementary Data, which can be viewed online at www.reproduction-online.org/supplemental/) and no significant correlations were observed in the fully dominant follicles (shown in Supplementary Data). diameters between groups. For statistical analyses the data in (D) were

Reproduction (2009) $137825-834$

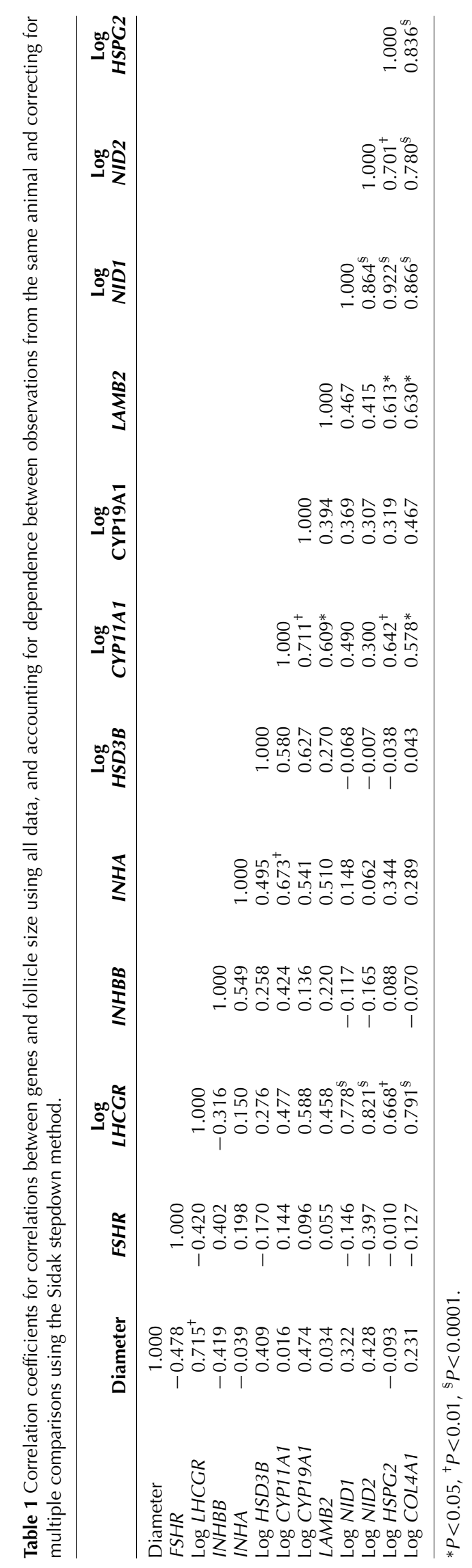

www.reproduction-online.org 

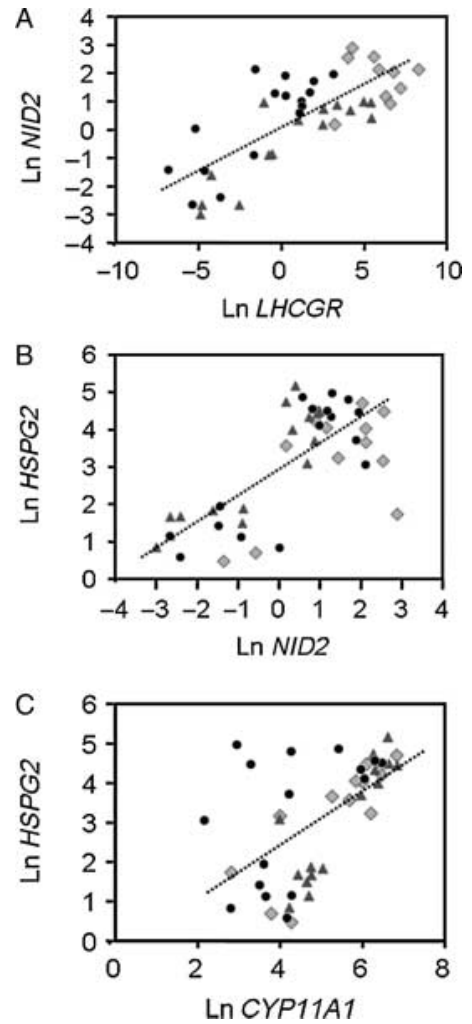

Figure 5 Scatter plots of mRNA levels of (A) Ln NID2 versus Ln $L H C G R$, (B) Ln HSPG2 versus Ln NID2, and (C) Ln HSPG2 versus Ln CYP11A1. circles, subordinate follicles; triangles, partially dominant follicles; diamonds, fully dominant follicles.

\section{Discussion}

During the later stages of follicle development, we measured in granulosa cells the level of expression of markers of maturation (FSHR, LHCGR, CYP11A1, HSD3B, CYP19A1, INHA and INHBB) and components of focimatrix (COL4A1, LAMB2, HSPG2, NID1 and -2). We also measured the volume density of components of focimatrix (components of laminin 111, HSPG2, NID1 and -2 ) in the membrana granulosa. With a view to identifying a role of focimatrix either in follicle dominance and/or granulosa cell maturation, we conducted our statistical analyses after removing the effect of follicle size. These analyses revealed that CYP11AI expression was upregulated in dominant follicles independently of increased size, and that CYP11A1 expression was highly and positively correlated with a number of focimatrix components, but not FSHR or LHCGR. This suggests either that focimatrix genes and CYP11A1 are all co-ordinately regulated, or that focimatrix induces the expression of CYP11A1 during follicle maturation. The latter is more likely as focimatrix is first observed at smaller sizes of follicles ( $5 \mathrm{~mm}$ follicle diameter) than is CYP11A1 (Irving-Rodgers et al. 2004).

Studies of follicular dominance have generally been conducted by examining known follicular genes

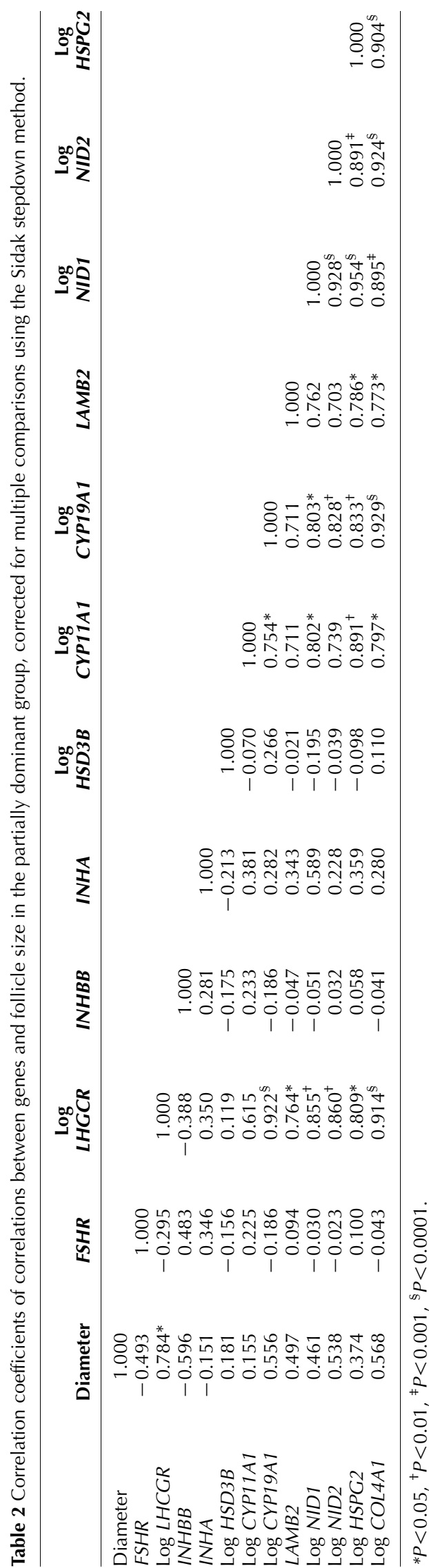

Reproduction (2009) 137 825-834 
(Bao et al. 1997, Yuan et al. 1998) or using gene expression profiling (Malhi et al. 2005, Zielak et al. 2007) with a view to understand the regulation of dominance. However, follicular dominance is also associated with a greater increase in size of the dominant follicle over the subordinate follicle leading eventually to its atresia. Before the onset of atresia in the subordinate follicle both dominant and subordinate follicles are increasing in size. Therefore, in the current study, subordinate, partially dominant and fully dominant follicles were first identified on size and histological assessment of the health of the three largest follicles in each pair of ovaries. In agreement with previously published data (reviewed in (Bao \& Garverick 1998, Webb et al. 1999, Fortune et al. 2001, Knight \& Glister 2003, Beg \& Ginther 2006)) follicle size increased across these groups and the expression of FSHR declined while LHCGR, CYP11A1, $H S D 3 B$ and CYP19A1 all increased and no changes were observed in INHA and INHBB. We then statistically removed the effect of size differential between the groups. This enabled us to identify molecules that were differentially altered specifically due to the degree of dominance, independent of changes in follicle size. Only CYP11A1 remained significantly different and was elevated in dominant follicles compared with subordinate follicles. No significant differences were observed between the groups in the expression of COL4A1, LAMB2, HSPG2 and NID1, but NID2 was significantly lower in the partially dominant group, even after adjusting for size. The volume density of focimatrix obtained by immunostaining with antisera against laminin 111 (which identifies any of the laminin chains $\alpha-1, \beta-1$ or $\gamma-1)$ was significantly elevated in dominant follicles even after adjusting for a size differential. No significant differences were observed in volume density for HSPG2 and NID1 or -2. Collectively, these results suggest that many of the markers of granulosa cell maturation identified here and previously in many other studies differed between dominant and subordinate follicles merely because the follicles were different in size. However, since both CYP11A1 expression and the focimatrix components found in laminin 111 were significantly elevated in dominant follicles, independent of size, it is suggested that these molecules could be important in either gaining or maintaining dominance.

Correlation analyses were also undertaken to gain insight into which genes could be co-ordinately regulated during the process of dominance. These analyses took into account the fact that more than one follicle was examined per animal, and that multiple correlations were conducted. Interestingly, CYP11A1 expression was correlated not only with CYP19A1 but also with LAMB2, HSPG2 and COL4A1 expression across all three groups of follicles. Additionally, in partially dominant follicles, NID1 and -2, HSPG2 and COL4A1 were significantly correlated with CYP19A1, suggesting that at least in the transition to gain dominance there is also an association between focimatrix and CYP19A1 expression. Recent studies have suggested that $\beta$-catenin can upregulate both CYP11A1 and CYP19A1 in rat granulosa cells (Parakh et al. 2006) and that $\beta$-catenin is an important co-activator of FSH-regulated oestrogen synthesis (Hernandez Gifford et al. 2009). $\beta$-catenin also plays a pivotal role in epithelial-mesenchymal transition (EMT; Shook \& Keller 2003, Oloumi et al. 2004). In epithelia, it associates with the junctions at the cell surface as part of focal adhesions, and in mesenchymal cells it is phosphorylated and translocated into the nucleus where it acts as a cofactor in activating gene transcription. While most of the literature focuses on cell-cell junctions and cadherins there is evidence for a role of integrin-linked kinase in EMT (Oloumi et al. 2004). Granulosa cell interaction with focimatrix is likely to be via integrins, and thus $\beta$-catenin could be the functional link between focimatrix and expression of steroidogenic enzymes.

Expression levels of COL4A1, NID1 and -2, and HSPG2 were highly correlated with each other, while LAMB2 was also significantly correlated with COLA41 and HSPG2. These genes encode different components of focimatrix which has the ultrastructural appearance of a basal lamina but without forming a sheet as conventional basal laminas do (Irving-Rodgers et al. 2004). Thus, focimatrix would be expected to contain basal lamina components in sufficiently correct proportions for basal lamina assembly. That $\angle A M B 2$ was not as tightly correlated with all other focimatrix components is not surprising as there is more than one type of laminin in follicular basal laminas (van Wezel et al. 1998). Overall, these results suggest co-regulation of the molecules that constitute focimatrix.

Highly significant correlations with $L H C G R$ expression and COL4A1, NID1 and -2 , and HSPG2 were also observed and may indicate that LH could upregulate focimatrix production, or that focimatrix could upregulate LHCGR. The latter is more likely as focimatrix appears during follicular development at $5 \mathrm{~mm}$ diameter (Irving-Rodgers et al. 2004), before the upregulation of LHCGR. Furthermore, in other preliminary unpublished results, we have been unable to demonstrate $\mathrm{LH}$ induction of focimatrix in vitro. Alternatively, induction of focimatrix and upregulation of LHCGR may occur coincidentally via independent mechanisms.

Nidogens function to cross-link molecules within basal lamina. NID1 and -2 can bind laminin $\gamma-1$, COL4 and HSPG2, thus cross-linking these components makes the basal lamina more rigid. They have overlapping functions, but are not identical as NID2 has lower affinity for laminin and can bind endostatin, whereas NID1 does not (Ho et al. 2008). During follicular development, these molecules are differentially regulated and are absent from the follicular basal lamina in the primordial 
follicles but appear at the early antral stage (McArthur et al. 2000, Irving-Rodgers \& Rodgers 2006). This is despite the follicular basal lamina of primordial follicles having all six collagen type IV chains and at least the laminin chains $\alpha-1, \beta-2$ and $\gamma-1$ (Rodgers et al. 1998, van Wezel et al. 1998). Nidogens are universally produced by mesenchymal cells even when present as a component of epithelial basal lamina (Ho et al. 2008). However, in the present study, we have shown that the granulosa cells express NID1 and -2, with NID2 mRNA levels being an order of magnitude greater than NID1. Other components of focimatrix, COL4A1, LAMB2 and HSPG2, were also expressed by granulosa cells, suggesting that the focimatrix is derived from the granulosa cells themselves. In the present study, there was not precise agreement between the results obtained for the mRNA levels and the volume density of the focimatrix. For example, NID2 mRNA levels were significantly different between the three groups whereas the volume density of NID2 was not. This may not be unexpected since extracellular matrices can have relatively long half lives.

Thus, in summary, we observed that dominant follicles independent of increasing follicle size have increased expression of CYP11A1 and focimatrix components contained in laminin 111. Additionally, CYP11A1 is highly correlated with the expression of a number of focimatrix genes. Since focimatrix precedes CYP11A1 expression during follicle growth (Irving-Rodgers et al. 2004) and first appears at follicular sizes smaller than follicular deviation, focimatrix may induce the expression of CYP11A1 and this process may be important for development or maintenance of follicular dominance. However, direct proof of this is still required.

\section{Materials and Methods}

\section{Tissue processing}

Pairs of ovaries were collected at the abattoir from 41 Bos taurus cows, visually assessed as non-pregnant. The largest two or three follicles were identified and dissected from the ovaries of 18 and 23 cows respectively. Each pair of ovaries had one corpus luteum at stage II and III (Ireland et al. 1980), indicating that the follicles were not in the ovulatory wave of the cycle, and thus eliminating any confounding effect of an LH surge. The external follicle diameter was measured with callipers and then cut open and a portion through the follicle wall $(\sim 2 \times 2 \times 2 \mathrm{~mm})$ was fixed in $2.5 \%$ glutaraldehyde in $0.1 \mathrm{M}$ phosphate buffer. An additional small section through the follicle wall $(\sim 2 \times 2 \times 2 \mathrm{~mm})$ was placed in Tissue Tek OCT compound (Miles Inc., Elkhart, IN, USA) and snap-frozen for immunohistochemistry. The remainder of the follicle was removed to Hanks balanced salt solution without calcium or magnesium (H 2387; Sigma Bio Science) and granulosa cells isolated, then placed in $500 \mu \mathrm{l} \mathrm{Trizol}$ (Invitrogen Aust. Pty Ltd) for extraction of RNA.

\section{Follicle classification}

For follicles collected from the same cow, the largest was classified as dominant and smaller follicle(s) classified as subordinate. Follicles were assessed as healthy or atretic based upon the morphology of the membrana granulosa and the presence or absence of apoptotic cells, as previously described (Irving-Rodgers et al. 2001, 2003). These morphological methods have previously been shown to classify follicles correctly as healthy or atretic on the basis of follicular fluid oestradiol levels (Irving-Rodgers et al. 2001, 2003). Follicles were assigned to one of three groups based upon the following classification regime: Group 1, largest follicle healthy and subordinate follicles atretic $(n=14)$; Group 2, all follicles healthy $(n=7)$; Group 3, largest follicle atretic and subordinate follicle(s) healthy $(n=11)$. Only healthy follicles were included in the study. The largest healthy follicles from Group 1 were designated as fully dominant $(n=14)$ since subordinate follicles in this group were atretic. The largest healthy follicles from Groups 2 and 3 were designated as partially dominant $(n=18)$, since subordinate follicles in these groups were healthy. The subordinate follicle class was derived from healthy follicles of Groups 2 and $3(n=16)$.

\section{Histology and immunohistochemisty}

For light microscopy, glutaraldehyde-fixed tissue was post-fixed in $1 \%$ osmium tetroxide and embedded in epoxy resin as previously described (Irving-Rodgers et al. 2002b) and $1 \mu \mathrm{m}$ thick sections were cut with glass knives using a Richert-Jung Ultracut E ultramicrotome (Leica Microsystems Pty Ltd, North Ryde, NSW, Australia), collected on plain glass slides and stained with aqueous $1 \%$ methylene blue in 1\% sodium tetraborate. OCT-embedded follicle walls were sectioned at $10 \mu \mathrm{m}$ using a CM 1800 Leica cryostat (Leica Microsystems Pty Ltd), and immunohistochemistry conducted as reported previously (Irving-Rodgers et al. 2002a). Unfixed sections were dried under vacuum for 5 min before fixation in either formalin or $100 \%$ ethanol, or left unfixed, depending upon the primary antibody to be applied. All slides were incubated in 10\% normal donkey serum (D-9663; Sigma Bio Science) in antibody diluent containing $0.55 \mathrm{M}$ sodium chloride and $10 \mathrm{mM}$ sodium phosphate $(\mathrm{pH} 7.2)$, for $20 \mathrm{~min}$ at room temperature. Sections were then incubated overnight with primary antibodies. The primary antibodies were rabbit anti-mouse laminin 111 from the EHS tumour (\#L 9393, Sigma Bio Science, 1:100 dilution, section fixed in 100\% ethanol), rat anti-human HSPG2 (\#A7L6 from Upstate Biotechnologies (Lake Placid, NY, USA), 1:100 dilution, section formalin fixed), rabbit anti-mouse NID1 (\#913, Dr M Dziadek (Dziadek et al. 1985), 1:200 dilution, unfixed section) and rabbit anti-mouse NID2 (\#1130 from Dr T Sasaki (Salmivirta et al. 2002), 1:800 dilution, unfixed section). The secondary antibodies used were biotin-SP-conjugated AffiniPure donkey-rabbit IgG (Cat \# 711-066-152, 1:200), donkey-mouse IgG (715-065-020, 1:100), or donkey-rat IgG (712-066-153, 1:100) depending upon primary antibody, followed by Cy3-conjugated-streptavidin (016-160-084, 1:100), from Jackson ImmunoResearch Laboratories, Inc. (West Grove, PA, USA), in antibody diluent. All incubations were carried out at 
room temperature in a humidified chamber and following fixation and incubation with primary or secondary antibodies or streptavidin-conjugated reagents, sections were washed $(3 \times 5 \mathrm{~min})$ in hypertonic PBS containing $0.274 \mathrm{M}$ sodium chloride, 5.4 M potassium chloride, $10 \mathrm{mM}$ sodium phosphate, $\mathrm{pH}$ 7.2. Sections were counterstained with the nuclear stain $4^{\prime}$, 6-diamidino-2-phenylindole dihydrochloride (DAPI) solution ( $3 \mu \mathrm{m}$; Molecular Probes, Eugene, OR, USA) for $10 \mathrm{~min}$ at room temperature and mounted in Dako fluorescent mounting media (Cat. \# S3023; Dako Corporation, Carpinteria, CA, USA). Sections were viewed with an Olympus BX50 microscope with epifluorescence attachment (Olympus Australia Pty Ltd, Mount Waverly, VIC, Australia) at a magnification of $\times 60$ and images (three per section) captured with a Spot RT digital camera (Diagnostic Instruments Inc., Sterling Heights, MI, USA). ImageJ software (http://rsb.info.nih.gov/ij/) was used to estimate the volume fraction of immunoreactive material in the membrana granulosa by selecting a region of interest excluding the follicular basal lamina and measuring the total area of immunopositive material per area of membrana granulosa.

\section{RNA extraction}

Total RNA was extracted from granulosa cells using Trizol reagent as per the manufacturer's recommendations. The quantity of total RNA was determined by spectrophotometry (Absorbance at $260 \mathrm{~nm}$ ) using the Beckman DU50 u.v. spectrophotometer (Beckman Coulter Australia Pty Ltd, Gladesville, NSW, Australia). Two microgram RNA was DNase treated (DNA-free, Ambion, Applied Biosystems, Melbourne, VIC, Australia) and then used to prepare cDNA. cDNA $(20 \mu \mathrm{l})$ was synthesised according to the manufacturer's instructions using $500 \mathrm{ng}$ random hexamers (GeneWorks, Adelaide, SA, Australia), $10 \mathrm{nmol}$ dNTP mix, 20 U RNaseOUT and 200 U Superscript III RT (Invitrogen).

\section{Real time RT-PCR}

Quantitative RT-PCR analysis of mRNA was performed using a Corbett RotorGene 6000 (Adelab Scientific, Adelaide, SA, Australia) and Real MasterMix, (Eppendorf, Quantum,
Brisbane, QLD, Australia) with SYBR Green as the fluorescence detector, according to the manufacturer's recommendations. The housekeeping gene was $18 \mathrm{~S}$ rRNA. Primers were designed across an exon boundary to amplify cDNAs (Table 3). Taq polymerase amplified PCR products were cloned into pCR II-TOPO plasmid vector; plasmids were transformed into Top $10 \mathrm{~F}^{\prime}$ competent Escherichia coli. Plasmid DNA was purified using a NucleoSpin kit (Macherey Nagel product supplied by Integrated Sciences, Sydney, NSW, Australia) and then sequenced to confirm the identity of the amplicon. PCR parameters were $95{ }^{\circ} \mathrm{C}$ for $15 \mathrm{~s}$ and $60{ }^{\circ} \mathrm{C}$ for $45 \mathrm{~s}$ for 40 cycles and data were analysed using Rotorgene software version 1.7. For quantitation of each gene the corresponding plasmid DNA was quantitated using a Nanodrop spectrophotometer (Nanodrop Technologies, Wilmington, DE, USA) and concentrations were calculated from absorbance at $260 \mathrm{~nm}$. Plasmid DNA for each gene was then serially diluted over 3 logs to establish a standard curve that encompassed the observed $C_{\mathrm{t}}$ values for the RNA samples (between $1 \mathrm{ng} / \mu \mathrm{l}$ and $1 \mathrm{fg} / \mu \mathrm{l}$ ). Concentration of RNA for each gene was normalised to the concentration of $18 \mathrm{~S}$ rRNA expressed as fmole mRNA/nmole $18 \mathrm{~S}$ rRNA.

\section{Statistical analyses}

All statistical calculations were performed using SAS Version 9.1 (SAS Institute Inc., Cary, NC, USA). Differences in expression between follicle groups (fully dominant, partially dominant and subordinate) were investigated using linear mixed effects models. Animal number was included as a random effect in the models to account for the dependence in follicles obtained from the same animal. To investigate differences in expression between the follicle groups, unrelated to follicular diameter, additional linear mixed effects models adjusted for follicular diameter were undertaken. In both adjusted and unadjusted analyses, data were examined for normality and were log transformed when necessary. All log transformed data were normally distributed. Where a significant difference was found across the three follicle groups, post-hoc tests were conducted to compare the follicle groups two at a time.

To calculate the correlations between the expressions of different genes, while accounting for the dependence between

Table 3 PCR primers and amplicon sizes.

\begin{tabular}{|c|c|c|c|c|c|}
\hline Gene name & $\begin{array}{l}\text { Gene } \\
\text { symbol }\end{array}$ & $\begin{array}{l}\text { Amplicon } \\
\text { size }(b p)\end{array}$ & Forward primer & Reverse primer & $\begin{array}{l}\text { GenBank accession } \\
\text { number }\end{array}$ \\
\hline $18 \mathrm{~S}$ rRNA & $18 \mathrm{~S}$ & 90 & $5^{\prime}$-agaaacggctaccacatccaa-3' & $5^{\prime}$-cctgtattgttatttttcgt-3' & DQ222453 \\
\hline FSH receptor & FSHR & 74 & $5^{\prime}$-tggcaagtgcttaatacctgtgtt-3' & $5^{\prime}$-tggvssgtgcttaatacctgtgtt-3' & NM_174061 \\
\hline $\mathrm{LH}$ receptor & LHCGR & 157 & $5^{\prime}$-gccactgctgtgcttttagaaa-3' & $5^{\prime}$-ccagccactcagttcactctca-3' & U87230 \\
\hline Inhibin- $\alpha$ & INHA & 93 & $5^{\prime}$-tgagcccgaggaccaagat-3' & $5^{\prime}$-ctcctcagcctctccagacat-3' & NM_174094 \\
\hline Inhibin $\beta-B$ & $I N H B B$ & 85 & $5^{\prime}$-cgtctccgagatcatcagctt-3' & $5^{\prime}$-tgccttcgttggagatgaaga-3' & NM_176852 \\
\hline $\begin{array}{l}\text { Cholesterol side-chain } \\
\text { cleavage }\end{array}$ & CYP11A1 & 85 & $5^{\prime}$-cactttcgccacatcgagaa-3' & $5^{\prime}$-tgaatgatataaactgactccaaattgc-3' & K02130 \\
\hline $\begin{array}{l}\text { 3ß-Hydroxysteroid } \\
\text { dehydrogenase }\end{array}$ & $H S D 3 B$ & 70 & $5^{\prime}$-agagaccatcatgaacgtcaatgt-3' & $5^{\prime}$-gtacgctggcctggacaca-3' & NM_776768 \\
\hline Aromatase & CYP19A1 & 141 & $5^{\prime}$-ggctatgtggacgtgttgacc-3' & $5^{\prime}$-tgagaaggagagcttgcctg-3' & NM_174305 \\
\hline Collagen type IV $\alpha-1$ & COLL4A1 & 104 & 5'-ttccaggcgactcaggg-3' & $5^{\prime}$-cgtgccaataacagttccgg-3' & XM_580317 \\
\hline Laminin $\beta-2$ & $L A M B 2$ & 63 & $5^{\prime}$-cccagccctactgcatcgt-3' & $5^{\prime}$-cgggagtcacacagaaagca-3' & XM_598402 \\
\hline Perlecan & HSPG2 & 64 & $5^{\prime}$-tcaggatcgagtcgtcgtctt-3' & $5^{\prime}$-gaccacgcagttcagatcca-3' & XM_584570 \\
\hline Nidogen 1 & NID1 & 106 & $5^{\prime}$-cgagttagcggcaaggtgaag-3' & $5^{\prime}$-gcccatggttcattaccacgta- $3^{\prime}$ & NM_001101155 \\
\hline Nidogen 2 & NID2 & 113 & $5^{\prime}$-gctttccttgcgcttctattga-3' & $5^{\prime}$-gggaaatcgtcgtccacatact-3' & XM_600125 \\
\hline
\end{tabular}


observations from the same animal, between-subject Pearson's correlation coefficients were calculated. This was equivalent to taking a mean of the repeated measurements from each animal and using these data to calculate the coefficient. As a large number of correlations were investigated using this approach, the $P$ values were corrected for multiple comparisons using the stepdown Sidak method. Where appropriate, log transformed data were used to ensure normally distributed data were analysed. In addition to an assessment of the correlations over all follicle groups, correlations within each group of follicles (in which each follicle was from a separate animal) were undertaken.

\section{Declaration of interest}

The authors declare that they have no conflicts of interest that would affect the impartiality of the conduct and reporting of these experiments.

\section{Funding}

The research was supported by the National Health and Medical Research Council of Australia, University of Adelaide and the Clive and Vera Ramaciotti Foundation. We thank T\&R Pastoral for donation of ovaries.

\section{Acknowledgements}

We thank Drs M Dziadek and T Sasaki for their generous donation of antibodies and Stephanie Morris and Nicholas Hatzirodos for their assistance in the conduct of these experiments.

\section{References}

Alexopoulos E, Shahid J, Ongley HZ \& Richardson MC 2000 Luteinized human granulosa cells are associated with endogenous basement membrane-like components in culture. Molecular Human Reproduction $6324-330$.

Bao B \& Garverick HA 1998 Expression of steroidogenic enzyme and gonadotropin receptor genes in bovine follicles during ovarian follicular waves: a review. Journal of Animal Science 76 1903-1921.

Bao B, Garverick HA, Smith GW, Smith MF, Salfen BE \& Youngquist RS 1997 Changes in messenger ribonucleic acid encoding luteinizing hormone receptor, cytochrome P450-side chain cleavage, and aromatase are associated with recruitment and selection of bovine ovarian follicles. Biology of Reproduction 56 1158-1168.

Beg MA \& Ginther OJ 2006 Follicle selection in cattle and horses: role of intrafollicular factors. Reproduction 132 365-377.

Berisha B, Schams D, Kosmann M, Amselgruber W \& Einspanier R 2000 Expression and localisation of vascular endothelial growth factor and basic fibroblast growth factor during the final growth of bovine ovarian follicles. Journal of Endocrinology 167 371-382.

Burns DS, Jimenez-Krassel F, Ireland JL, Knight PG \& Ireland JJ 2005 Numbers of antral follicles during follicular waves in cattle: evidence for high variation among animals, very high repeatability in individuals, and an inverse association with serum follicle-stimulating hormone concentrations. Biology of Reproduction 73 54-62.

Campbell BK, Souza C, Gong J, Webb R, Kendall N, Marsters P, Robinson G, Mitchell A, Telfer EE \& Baird DT 2003 Domestic ruminants as models for the elucidation of the mechanisms controlling ovarian follicle development in humans. Reproduction Supplement 61 429-443.
Crowe MA, Kelly P, Driancourt MA, Boland MP \& Roche JF 2001 Effects of follicle-stimulating hormone with and without luteinizing hormone on serum hormone concentrations, follicle growth, and intrafollicular estradiol and aromatase activity in gonadotropin-releasing hormoneimmunized heifers. Biology of Reproduction 64 368-374.

Dziadek M, Paulsson M \& Timpl R 1985 Identification and interaction repertoire of large forms of the basement membrane protein nidogen. EMBO Journal 4 2513-2518.

Evans AC \& Fortune JE 1997 Selection of the dominant follicle in cattle occurs in the absence of differences in the expression of messenger ribonucleic acid for gonadotropin receptors. Endocrinology 138 2963-2971.

Fortune JE 1994 Ovarian follicular growth and development in mammals. Biology of Reproduction 50 225-232.

Fortune JE, Rivera GM, Evans AC \& Turzillo AM 2001 Differentiation of dominant versus subordinate follicles in cattle. Biology of Reproduction 65 648-654.

Ginther OJ, Kot K, Kulick LJ \& Wiltbank MC 1997 Emergence and deviation of follicles during the development of follicular waves in cattle. Theriogenology 48 75-87.

Ginther OJ, Beg MA, Donadeu FX \& Bergfelt DR 2003 Mechanism of follicle deviation in monovular farm species. Animal Reproduction Science 78 239-257.

Hampton JH, Bader JF, Lamberson WR, Smith MF, Youngquist RS \& Garverick HA 2004 Gonadotropin requirements for dominant follicle selection in GnRH agonist-treated cows. Reproduction 127 695-703.

Hernandez Gifford JA, Hunzicker-Dunn ME \& Nilson JH 2009 Conditional deletion of beta-catenin mediated by Amhr2cre in mice causes female infertility. Biology of Reproduction [in press]. DOI:10.1095/ biolreprod.108.072280.

Ho MS, Bose K, Mokkapati S, Nischt R \& Smyth N 2008 Nidogens extracellular matrix linker molecules. Microscopy Research and Technique 71 387-395.

Huet C, Monget P, Pisselet C \& Monniaux D 1997 Changes in extracellular matrix components and steroidogenic enzymes during growth and atresia of antral ovarian follicles in the sheep. Biology of Reproduction 56 1025-1034.

Ireland JJ, Murphee RL \& Coulson PB 1980 Accuracy of predicting stages of bovine estrous cycle by gross appearance of the corpus luteum. Journal of Dairy Science 63 155-160.

Irving-Rodgers HF \& Rodgers RJ 2006 Extracellular matrix of the developing ovarian follicle. Seminars in Reproductive Medicine 24 195-203.

Irving-Rodgers HF, vanWezel IL, Mussard ML, Kinder JE \& Rodgers RJ 2001 Atresia revisited: two basic patterns of atresia of bovine antral follicles. Reproduction 122 761-775.

Irving-Rodgers HF, Bathgate RA, Ivell R, Domagalski R \& Rodgers RJ 2002a Dynamic changes in the expression of relaxin-like factor (INSL3), cholesterol side-chain cleavage cytochrome p450, and 3beta-hydroxysteroid dehydrogenase in bovine ovarian follicles during growth and atresia. Biology of Reproduction 66 934-943.

Irving-Rodgers HF, Mussard ML, Kinder JE \& Rodgers RJ 2002b Composition and morphology of the follicular basal lamina during atresia of bovine antral follicles. Reproduction 123 97-106.

Irving-Rodgers HF, Krupa M \& Rodgers RJ 2003 Cholesterol side-chain cleavage cytochrome P450 and 3beta-hydroxysteroid dehydrogenase expression and the concentrations of steroid hormones in the follicular fluids of different phenotypes of healthy and atretic bovine ovarian follicles. Biology of Reproduction $692022-2028$.

Irving-Rodgers HF, Harland ML \& Rodgers RJ 2004 A novel basal lamina matrix of the stratified epithelium of the ovarian follicle. Matrix Biology 23 207-217.

Irving-Rodgers HF, Catanzariti KD, Aspden WJ, D'Occhio MJ \& Rodgers RJ 2006a Remodeling of extracellular matrix at ovulation of the bovine ovarian follicle. Molecular Reproduction and Development 73 1292-1302.

Irving-Rodgers HF, Friden BE, Morris SE, Mason HD, Brannstrom M, Sekiguchi K, Sanzen N, Sorokin LM, Sado Y, Ninomiya Y et al. 2006b Extracellular matrix of the human cyclic corpus luteum. Molecular Human Reproduction 12 525-534.

Jaiswal RS, Singh J \& Adams GP 2004 Developmental pattern of small antral follicles in the bovine ovary. Biology of Reproduction 71 1244-1251. 
Knight PG \& Glister C 2003 Local roles of TGF-beta superfamily members in the control of ovarian follicle development. Animal Reproduction Science 78 165-183.

Lussier JG, Matton P \& Dufour JJ 1987 Growth rates of follicles in the ovary of the cow. Journal of Reproduction and Fertility 81 301-307.

Malhi PS, Adams GP \& Singh J 2005 Bovine model for the study of reproductive aging in women: follicular, luteal, and endocrine characteristics. Biology of Reproduction 73 45-53.

McArthur ME, Irving-Rodgers HF, Byers S \& Rodgers RJ 2000 Identification and immunolocalization of decorin, versican, perlecan, nidogen, and chondroitin sulfate proteoglycans in bovine small-antral ovarian follicles. Biology of Reproduction 63 913-924.

Oloumi A, McPhee T \& Dedhar S 2004 Regulation of E-cadherin expression and beta-catenin/Tcf transcriptional activity by the integrin-linked kinase. Biochimica et Biophysica Acta 1691 1-15.

Parakh TN, Hernandez JA, Grammer JC, Weck J, Hunzicker-Dunn M, Zeleznik AJ \& Nilson JH 2006 Follicle-stimulating hormone/cAMP regulation of aromatase gene expression requires beta-catenin. PNAS 103 12435-12440.

Quirk SM, Hickey GJ \& Fortune JE 1986 Growth and regression of ovarian follicles during the follicular phase of the oestrous cycle in heifers undergoing spontaneous and PGF-2 alpha-induced luteolysis. Journal of Reproduction and Fertility 77 211-219.

Rodgers HF, Irvine CM, van Wezel IL, Lavranos TC, Luck MR, Sado Y, Ninomiya Y \& Rodgers RJ 1998 Distribution of the alpha1 to alpha6 chains of type IV collagen in bovine follicles. Biology of Reproduction 59 1334-1341.

Salmivirta K, Talts JF, Olsson M, Sasaki T, Timpl R \& Ekblom P 2002 Binding of mouse nidogen-2 to basement membrane components and cells and its expression in embryonic and adult tissues suggest complementary functions of the two nidogens. Experimental Cell Research 279 188-201.

Shook D \& Keller R 2003 Mechanisms, mechanics and function of epithelial-mesenchymal transitions in early development. Mechanisms of Development 120 1351-1383.

Tian XC, Berndtson AK \& Fortune JE 1995 Differentiation of bovine preovulatory follicles during the follicular phase is associated with increases in messenger ribonucleic acid for cytochrome P450 side-chain cleavage, 3 beta-hydroxysteroid dehydrogenase, and P450 17 alphahydroxylase, but not P450 aromatase. Endocrinology 136 5102-5110.

Valdez KE, Cuneo SP \& Turzillo AM 2005 Regulation of apoptosis in the atresia of dominant bovine follicles of the first follicular wave following ovulation. Reproduction 130 71-81.

Webb R, Campbell BK, Garverick HA, Gong JG, Gutierrez CG \& Armstrong DG 1999 Molecular mechanisms regulating follicular recruitment and selection. Journal of Reproduction and Fertility 54 33-48.

van Wezel IL, Rodgers HF \& Rodgers RJ 1998 Differential localization of laminin chains in bovine follicles. Journal of Reproduction and Fertility 112 267-278.

Xu Z, Garverick HA, Smith GW, Smith MF, Hamilton SA \& Youngquist RS 1995 Expression of follicle-stimulating hormone and luteinizing hormone receptor messenger ribonucleic acids in bovine follicles during the first follicular wave. Biology of Reproduction 53 951-957.

Yamada S, Fujiwara H, Honda T, Higuchi T, Nakayama T, Inoue T, Maeda M \& Fujii S 1999 Human granulosa cells express integrin alpha2 and collagen type IV: possible involvement of collagen type IV in granulosa cell luteinization. Molecular Human Reproduction 5 607-617.

Yuan W, Bao B, Garverick HA, Youngquist RS \& Lucy MC 1998 Follicular dominance in cattle is associated with divergent patterns of ovarian gene expression for insulin-like growth factor (IGF)-I, IGF-II, and IGF binding protein-2 in dominant and subordinate follicles. Domestic Animal Endocrinology 15 55-63.

Zielak AE, Forde N, Park SD, Doohan F, Coussens PM, Smith GW, Ireland JJ, Lonergan P \& Evans AC 2007 Identification of novel genes associated with dominant follicle development in cattle. Reproduction, Fertility, and Development 19 967-975.

Received 20 November 2008

First decision 6 January 2009

Revised manuscript received 16 February 2009

Accepted 4 March 2009 